\title{
Editorial
}

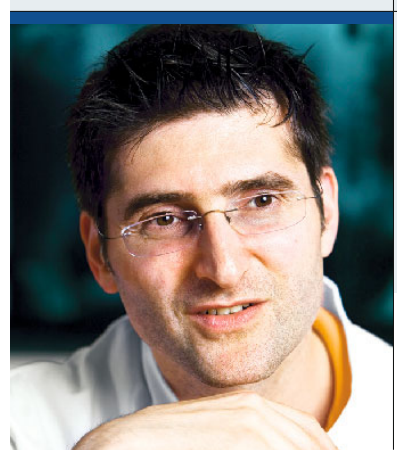

Während sich die Geisteswissenschaften und die Psychologie

sich seit vielen Jahren mit den Sexualstörungen von Frauen

befassen, haben die Mediziner die Bedeutung der weiblichen

Sexualität und Ihrer Störungen lange vernachlässigt."

Prof. Dr. med. Frank Sommer,

Universitätsprofessor für Männergesundheit am Universitätsklinikum

Hamburg-Eppendorf, Präsident der Deutschen Gesellschaft für

Mann und Gesundheit

\section{Sexualität der Frau im Fokus}

$\mathrm{S}$ eit Jahrtausenden wird der romantischen Liebe in Literatur, Kunst und Musik gehuldigt. Kein anderes Gefühl inspiriert und motiviert uns Menschen so sehr wie die Liebe. Verliebte Menschen sind in einem Zustand der Euphorie und Glückseligkeit, ähnlich der Manie, vor allem hervorgerufen durch Dopamin, den wichtigsten zentralen Neurotransmitter, der Belohnung, Begehren, Abhängigkeit und Euphorie steuert. Verliebte sind „high“. Dopamin stimuliert die gleichen Hirnareale, die durch exogene opioide Drogen wie Kokain aktiviert werden, während die Serotonin-Spiegel auf die Level sinken, die wir von psychotischen Patienten kennen.

\section{Die verschiedenen Sprachen der Liebe}

Der antike Philosoph Platon analysierte die Liebe und unterteilte sie in Éros, Philía und Agápe. Éros bezeichnete die sinnlich-erotische Liebe, das Begehren des geliebten Menschen, die Intensität und Leidenschaft, die uns nach physischer Vereinigung sehnen lässt. In unserer abendländischen Philosophie manifestiert sich die romantische Liebe in der körperlichen, sexuellen Vereinigung der beiden Liebenden. Dieses sexuelle Begehren zeigt die Affektion füreinander, die sexuelle Vereinigung ist eine wichtige Form der Kommunikation sowohl auf der emotionalen als auch auf der körperlichen Ebene. Denn körperliche Liebe und Nähe ermöglichen uns die außerordentlich intensive Kommunikation unserer emotionalen Liebe. Während dieser körperlichen Kommunikation kommt es durch Oxytocin, das wichtigste Bindungshormon, ausgeschüttet während des Orgasmus, zu einer Stabilisierung und Festigung der Bindung beider Partner. So haben Störungen der Sexualität einen immensen negativen Einfluss auf die Beziehung und die Lebensqualität der be- troffenen Frauen und Männer, denn die sexuelle Zufriedenheit ist assoziiert mit der emotionalen $\mathrm{Zu}$ friedenheit in der Beziehung.

\section{Aufholbedarf der Mediziner}

Während sich die Geisteswissenschaften und die Psychologie seit vielen Jahren mit den Sexualstörungen von Frauen befassen, haben die Mediziner die Bedeutung der weiblichen Sexualität und ihrer Störungen lange vernachlässigt. In den letzten zehn Jahren jedoch sind durch die Entwicklung der medikamentösen Therapie der männlichen Sexualstörungen unwiderrufliche und gewaltige Veränderungen und Fortschritte in der Erforschung weiblicher Sexualität und deren Störungen erfolgt. Wir Urologen sind und waren in diesem Gebiet „Frauen und Männer der ersten Stunde“ und haben eine wichtige Kompetenz und Verantwortung in der Behandlung von Sexualstörungen des Paares. Denn die erektile Dysfunktion, die wir behandeln, betrifft nicht nur den Mann sondern hat auch einen schwerwiegenden Einfluss auf die Sexualität der Partnerin. Weiterhin sind Urologen wichtige Ansprechpartner für Frauen mit Harnwegsinfekten, Harninkontinenz und Erkrankungen der Harnwege - alles Komorbiditäten, die in hohem Maße mit Sexualstörungen der Frauen assoziiert sind. Das Ziel der Sexualmedizin ist eine kompetente und umfassende Diagnose und Behandlung des Paares. Nutzen wir als Urologen die Chance ein aktiver Ansprechpartner und kompetente Vertrauensperson auch für unsere weiblichen Patienten zu sein.

Ihr

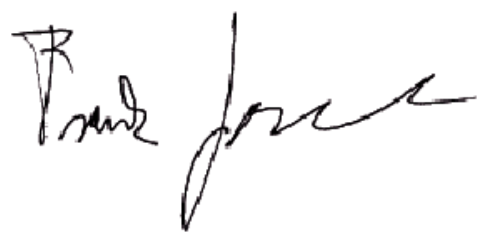

